\title{
COMPOSIÇÃO E DIVERSIDADE NO CERRADO DO LESTE DE MATO GROSSO DO SUL, BRASIL ${ }^{1}$
}

\author{
Renato Augusto Ferreira de Lima², Juliana Gastaldello Rando e Klaus Duarte Barreto $^{4}$
}

RESUMO - Neste estudo, avaliaram-se a composição e diversidade no Cerrado em três áreas do Leste de Mato Grosso do Sul, uma das regiões mais ameaçadas e menos estudadas do Cerrado brasileiro. Para tanto, levantaram-se as espécies vasculares em trilhas percorridas em diferentes fisionomias desse bioma, com enfoque especial para as espécies arbustivas e arbóreas. Adicionalmente, nas áreas de Cerrado sensu stricto foram instaladas 30 parcelas de $10 \times 3 \mathrm{~m}$, nas quais foram amostrados apenas indivíduos lenhosos $>1 \mathrm{~m}$ de altura. No geral, foram levantadas 220 espécies, 150 gêneros e 65 famílias de diferentes formas de vida, incluindo espécies consideradas raras nos Cerrados brasileiros e possíveis novas ocorrências nos Cerrados de Mato Grosso do Sul. A riqueza de espécies arbustivas e arbóreas no Cerrado sensu stricto foi alta (79-101 espécies por área). Houve baixa similaridade florística entre as áreas estudadas, de modo que apenas 50 espécies foram comuns a todas elas. O estudo da vegetação lenhosa por meio de parcelas (total de 651 indivíduos e 105 espécies) revelou uma diferença na riqueza média, diversidade (índice de Shannon) e dominância (Berger-Parker) entre as áreas estudadas. Adicionalmente, a densidade relativa das espécies e a composição florística foram bastante variáveis entre as áreas estudadas (similaridade entre 0,42 e 0,53). Tais resultados colocam as áreas estudadas entre as mais ricas áreas de Cerrado sensu stricto do Brasil, mostrando que áreas marginais de Cerrado podem ser tão ricas quanto suas áreas centrais, mesmo que através da contribuição de elementos florísticos de outras formações florestais. Os resultados reforçam ainda a existência de elevada heterogeneidade florística no Cerrado, mesmo em distâncias relativamente curtas $(\leq 60 \mathrm{~km})$, que pode ser desencadeada por diferenças entre fragmentos em relação à característica de solo, histórico de perturbação e proximidade de outras formações vegetais.

Palavras-chave: Fitossociologia; Levantamento florístico; Riqueza de espécies

\section{COMPOSITION AND DIVERSITY IN THE CERRADO OF EASTERN MATO GROSSO DO SUL, BRAZIL}

\begin{abstract}
The composition and diversity of Cerrado were evaluated in three different sites in eastern Mato Grosso do Sul, one of the most threatened and poorly studied areas in the Brazilian Cerrado. Vascular species were surveyed along trails in different Cerrado physiognomies, with special regard to shrub and tree species. Additionally, in the areas of cerrado sensu stricto 30 plots of $10 \times 3 \mathrm{~m}$ were installed, wherein only woody individuals $>1 \mathrm{~m}$ tall were sampled. Overall, 220 species, 150 genera and 65 families of different life forms were surveyed, including species considered as rare in the Brazilian Cerrado and possible new records for the Cerrado of Mato Grosso do Sul. Shrub and tree species richness in the cerrado sensu stricto was high (79-101 species per site). There was a low floristic similarity among sites: only 50 species were common to all of them. The study of the woody vegetation by plots (total of 651 individuals of 105 species) revealed a difference in average richness, diversity (Shannon index) and dominance (Berger-Parker) among the studied sites. In addition, species relative densities and floristic composition were quite variable among sites (similarity from 0.42 to 0.53). These results place the studied sites among the richest areas of cerrado sensu stricto in Brazil, showing that marginal areas of Cerrado can be as rich as their core areas, even by the contribution
\end{abstract}

\footnotetext{
${ }^{1}$ Recebido em 20.06.2011 aceito para publicação em 10.11.2014.

${ }^{2}$ Universidade de São Paulo, Programa de Pós-Graduação em Ecologia, São Paulo, SP - Brasil. E-mail: <raflima@usp.br>.

${ }^{3}$ Universidade de São Paulo, Programa de Pós-Graduação em Botânica, São Paulo, SP - Brasil. E-mail: <ju_rando@hotmail.com>.

${ }^{4}$ Casa da Floresta Assessoria Ambiental, Piracicaba, SP - Brasil. E-mail: <klaus@casadafloresta.com.br>.
} 
of floristic elements of other forest formations. The results also reinforce the existence of a high floristic heterogeneity in the Cerrado, even at relatively short distances ( $\leq 60 \mathrm{~km})$, which can be triggered by differences between fragments in respect to soil characteristics, disturbance history and proximity to other forest formations.

Keywords: Phytosociology; Floristic survey; Species richness.

\section{INTRODUÇÃO}

Cerrado é o termo comumente utilizado para caracterizar as savanas que ocupam o Planalto Central do Brasil e outras regiões no país, mas se estendem pelo Paraguai e Bolívia (RATTER et al., 2003; FIASCHI; PIRANI, 2009). Trata-se de um complexo vegetacional com fisionomias que vão desde formações campestres até florestais (VELOSO, 1992), cuja composição e estrutura da vegetação são determinadas por fatores como solo, presença de fogo e o histórico de distúrbios (COUTINHO, 1978; RATTER et al., 1997; RIZZINI, 1997). Depois da Floresta Amazônica, o Cerrado é o maior bioma brasileiro, cobrindo originalmente mais de 2 milhões de $\mathrm{km}^{2}$. Contudo, grande parte desse bioma já foi convertida em áreas de pastagem e agricultura, de modo que poucos remanescentes estão sob proteção em Unidades de Conservação (HARRIS et al., 2005; PAGOTTO; SOUZA, 2006). Considerado um dos hotspots mundiais, apenas $21 \%$ da extensão original do Cerrado resta inalterada, ameaçando sua enorme diversidade e seus altos índices de endemismo (CASTRO et al., 1999).

Uma das características mais marcantes do Cerrado é a baixa similaridade florística ao longo de sua extensão (RATTER et al., 1997; CASTRO et al., 1999; BRIDGEWATER et al., 2004). Entre as espécies lenhosas, por exemplo, Ratter et al. (2003) citaram mais de 65\% das espécies do Cerrado como muito raras, ou seja, possuem frequência d" 2,5\%. Entre as espécies não lenhosas, apesar de o conhecimento taxonômico e biogeográfico ser bastante limitado (CASTRO et al., 1999), há heterogeneidade florística semelhante (ROSSATO et al., 2008). Essa heterogeneidade pode ser uma expressão das diferentes sete províncias florísticas do Cerrado (RATTER et al., 2006). Porém, mesmo entre diferentes fitofisionomias de uma mesma área de Cerrado, há grande variação na composição das espécies (VELOSO, 1992; RIZZINI, 1997; MARIMONJÚNIOR; HARIDASAN, 2005). Adicionalmente, estudos realizados no Cerrado têm revelado que diferentes localidades são geralmente distintas em respeito à identidade de suas espécies mais importantes (FELFILI; SILVA-JÚNIOR, 1993; SAPORETTI-JÚNIOR et al., 2003;

Revista Árvore, Viçosa-MG, v.39, n.1, p.9-24, 2015
BALDUINO et al., 2005; NERI et al., 2007). Tal característica se expressa mesmo entre áreas relativamente próximas umas das outras (ANDRADE et al., 2002; FONSECA; SILVA-JÚNIOR, 2004).

Apesar da alta riqueza estimada para o Cerrado (total de 3.000 a 7.000 espécies de angiospermas CASTRO et al., 1999), o número de espécies ocorrentes em certa localidade é bem menor. Entre as espécies arbustivas e arbóreas, este número raramente excede 120 espécies (FELFILI; SILVA-JÚNIOR, 1993; FELFILI et al., 2002). Ratter et al. (2003), usando metodologia padronizada, encontraram valores médios de riqueza entre 32 e 79 espécies lenhosas por sítio amostrado, com áreas nos Estados de Goiás, Tocantins e Mato Grosso, representando aqueles com maiores médias (79, 72 e 65 espécies, respectivamente). Para o Estado de Mato Grosso do Sul, onde este estudo foi realizado, o valor médio encontrado pelos autores foi de 58 espécies.

Apesar do crescente número de estudos, existem várias lacunas de conhecimento no Cerrado brasileiro. O Mato Grosso do Sul é um dos Estados brasileiros com menor volume de dados disponíveis (RATTER et al., 2003), especialmente na sua porção Leste (extrapantanal), onde existem pouquíssimos estudos (e.g. RATTER et al., 2001; PAGOTTO; SOUZA, 2006). Esta região do Estado corresponde ao chamado Distrito Florestal de Mato Grosso do Sul, que, durante a década de 1970 (auge da política de incentivo florestal brasileira), teve extensas áreas de Cerrado convertidas em plantios florestais e pastagens. Os Municípios de Três Lagoas e Brasilândia, por exemplo, sofreram reduções de 40 e $74 \%$ da vegetação original, respectivamente (MERCADANTE, 1994). Assim, entre 1965 e 1992 o Cerrado nessa região do país sofreu espantosa redução, de modo que fitofisionomias como o Cerrado sensu stricto e o Cerradão foram praticamente extintas. Adicionalmente, o atual estado de conservação dos poucos remanescentes é bastante precário (PAGOTTO; SOUZA, 2006). Tais aspectos tornam a região particularmente vulnerável (CASTRO et al., 1999) e a realização de estudos científicos, imprescindível. 
Nesse contexto, este estudo teve como objetivo descrever a composição e riqueza da flora vascular em fragmentos de Cerrado nos Municípios de Três Lagoas, Brasilândia e Selvíria, todos no Leste de Mato Grosso do Sul. De maneira complementar, parcelas foram instaladas em fragmentos de Cerrado sensu stricto, visando comparar a composição, riqueza e diversidades entre esses municípios. Assim, além da elaboração de uma lista de espécies e da descrição da riqueza e diversidade dos fragmentos de Cerrado sensu stricto da região, foram considerados os seguintes aspectos: a composição florística dos fragmentos no Leste de Mato Grosso do Sul é comparável à encontrada nas demais regiões do Cerrado brasileiro? E a riqueza de espécies arbustivas e arbóreas em Cerrado sensu stricto? A alta dissimilaridade florística entre áreas de Cerrado também se expressa na escala espacial estudada?

\section{MATERIAL E MÉTODOS}

\section{1. Área de estudo}

A área de estudo pertence à Bacia do Alto Rio Paraná, Municípios de Três Lagoas, Brasilândia e Selvíria, Leste de Mato Grosso do Sul. O clima é Tropical Quente Úmido, e os solos têm baixa disponibilidade de nutrientes e altos teores de alumínio (IBGE, 1997). Predominam os Latossolos Vermelho-Escuros Distróficos, que se desenvolvem sobre a Formação Marília, entre as cotas altitudinais de 270 e 400 m (MERCADANTE, 1994). Dados pluviométricos de um município vizinho (Castilho, SP) indicaram precipitação anual média de $1.240 \mathrm{~mm}$, com estação seca entre junho e agosto. Segundo Ratter et al. (1997; 2003), a vegetação pertence à região florística Centro-Oeste do Cerrado, estando relativamente próxima ao contato com as florestas estacionais do Estado de São Paulo. A paisagem local caracteriza-se por fragmentos pequenos e geralmente alterados em uma paisagem dominada pela agropecuária e plantios de eucalipto (PAGOTTO; SOUZA, 2006).

O estudo foi conduzido em fazendas de produção de eucalipto que abrigam alguns dos últimos remanescentes de Cerrado da região. Foram amostrados fragmentos em três hortos de produção diferentes: (i)

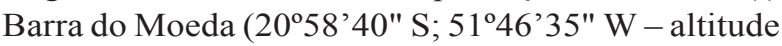
aproximada de $300 \mathrm{~m}$ ); (ii) Rio Verde (205' $35^{\prime \prime}$ S; $52^{\circ} 15^{\prime} 57^{\prime \prime}$ W - altitude aproximada de $350 \mathrm{~m}$ ); e (iii) Matão (20²6’04" $\mathrm{S} ; 51^{\circ} 48^{\prime} 06^{\prime \prime} \mathrm{W}$ - altitude aproximada de $400 \mathrm{~m}$ ). Esses hortos ficam próximos à fronteira com o Estado de São Paulo e estão separados entre si por uma distância de aproximadamente $60 \mathrm{~km}$, exceto entre Moeda e Rio Verde, cuja distância em linha reta é de $45 \mathrm{~km}$. Os fragmentos foram previamente selecionados de acordo com sua representatividade na área estudada e seu estado de conservação.

\subsection{Levantamento dos dados}

O levantamento das espécies vasculares foi realizado de maneira expedita, ao longo de trilhas, com atenção especial à flora arbustivo-arbórea; contudo ervas, subarbustos e lianas também foram amostrados. Em cada trilha, o levantamento foi realizado por três pessoas até que registros novos não fossem feitos em intervalos menores que $10 \mathrm{~min}$. Foram incluídas apenas as seguintes fitofisionomias: Cerradão, Cerrado sensu stricto, campo sujo, buritizal e campo úmido (nomenclatura adaptada de VELOSO, 1992), ou seja, não foram consideradas as formações florestais ribeirinhas, que mais se assemelham às formações florestais estacionais ocorrentes no Estado de São Paulo. No total foram amostrados sete fragmentos de Cerrado sensu stricto, quatro de campos sujos, dois de Cerrados sensu stricto em transição para Cerradão e um fragmento de Cerradão, de campo úmido e de buritizal. Nas áreas de Cerrado sensu stricto, um levantamento por parcelas (detalhes abaixo) foi feito de maneira complementar ao estudo florístico, visando caracterizar, de maneira mais completa, a flora local. Nas áreas cuja identificação em campo não foi possível, material estéril ou reprodutivo foi coletado para consulta à literatura taxonômica, identificação em herbário e consulta a especialistas, quando necessário. A classificação botânica adotada seguiu o APG II (2003). O material foi coletado sob a série de J.G. Rando e depositado nos herbários CTES (IBONE-Argentina) e ESA (ESALQ/USP).

Visando estimar a riqueza e diversidade de espécies arbustivas e arbóreas, foi realizado um estudo complementar ao levantamento florístico geral. Este estudo foi realizado apenas em fragmentos de Cerrado sensu stricto. Em função da baixa disponibilidade de fragmentos bem conservados dessa fitofisionomia, um dos fragmentos amostrados foi de Cerrado sensu stricto em transição para Cerradão. Parcelas de 10×3 $\mathrm{m}$ foram instaladas perpendicularmente e a uma distância mínima de $10 \mathrm{~m}$ dos limites do fragmento $(100 \mathrm{~m}$ de distância entre unidades amostrais). Foram amostrados

Revista Árvore, Viçosa-MG, v.39, n.1, p.9-24, 2015 
10 pontos em cada horto, num total de 30 unidades amostrais. Para cada indivíduo, foram anotados a espécie e o diâmetro do caule à altura do solo (DAS). Indivíduos mortos não foram avaliados e indivíduos vivos, porém sem folhas, foram considerados como uma mesma morfoespécie, mas foram excluídos das análises.

\subsection{Análise dos dados}

Para testar diferenças de composição de espécies entre os hortos estudados, foi aplicada a análise Multi-Response Permutation Procedures - MRPP (distância de Sørensen e opção de Weighting recomendada pelo programa) e a análise de espécies indicadoras ISA; teste de Monte Carlo executado com 10.000 randomizações; á $=10 \%$ ), que se baseia na abundância e frequência para identificar espécies com ocorrência preferencial em algum tipo de ambiente, no caso os hortos estudados. Ambas foram realizadas através do programa PcOrd versão 4.10 (McCUNE; MEFFORD, 1999) e apenas para os dados coletados no interior das parcelas estudadas. Para as análises sociológicas, foram utilizadas as fórmulas descritas em Mueller-Dombois e Ellenberg (1974). Os valores de densidade e área basal absoluta foram padronizados antes das análises e de acordo com a área amostral de classe de tamanho avaliada. A área basal foi obtida através da fórmula da área do círculo $\left(A=ð r^{2}\right)$, assumindo os caules mensurados como circulares. Para indivíduos com vários fustes, foram somadas as áreas basais calculadas para cada fuste individualmente.

Foi estimado o número máximo de espécies por horto e para os três hortos juntos, utilizando o estimador não paramétrico Jackknife de primeira e de segunda ordem, através do programa EstimateS versão 7.5 e 5.000 randomizações (COLWELL, 2005). A riqueza de espécies foi comparada por um número comum de indivíduos pela curva de rarefação (GOTELLI; COLWELL, 2001). Além da riqueza, a diversidade de Shannon ( $H^{\prime}$ ') e a dominância de BergerParker $(d)$ foram calculadas para cada horto. Essas análises (rarefação, diversidade e dominância) foram executadas com 10.000 randomizações pelo programa EcoSim versão 7 (GOTELLI; ENTSMINGER, 2001). A similaridade florística foi calculada através do índice de Chao et al. (2005), que corrige a similaridade entre amostras incompletas, também executada pelo programa EstimateS e 5.000 randomizações. Todas as comparações foram feitas baseadas nos Intervalos de Confiança $(\alpha=5 \%)$, gerados pelos próprios programas.

\section{RESULTADOS}

\subsection{Florística geral}

Foram realizados 699 registros, que totalizaram 220 espécies (Tabela 1), pertencentes a 150 gêneros e 65 famílias botânicas (total de espécies por horto: Moeda: 139; Rio Verde: 113; e Matão: 101 espécies). As 10 famílias mais ricas em número de espécies foram: Fabaceae (38 espécies), Myrtaceae (18), Bignoniaceae (12), Malpighiaceae e Rubiaceae (8), Annonaceae (7) e Asteraceae, Erythroxylaceae, Euphorbiaceae e Malvaceae (6). Juntas, essas famílias abrangeram 53\% de todas as espécies encontradas. Essa ordem foi basicamente a mesma para os hortos individualmente. Os gêneros mais ricos (mais de quatro espécies) foram: Eugenia, Erythroxylum, Tabebuia, Bauhinia, Byrsonima, Myrcia e Ouratea ( $78 \%$ dos gêneros estiveram representados por apenas uma espécie). Considerando apenas espécies arbustivas e arbóreas nos fragmentos de Cerrado sensu stricto, foi encontradas 158 espécies, distribuídas, da seguinte forma entre hortos: Moeda: 101; Rio Verde: 100; e Matão: 79 espécies.

Algumas espécies foram mais frequentes que outras, com considerável variação entre os hortos (Tabela 1). Apenas 50 espécies foram comuns a todos os hortos. Entre estas, as mais frequentes foram: Coccoloba mollis Casar. (16 registros), Alibertia edulis (Rich.) A. Rich ex DC. (15), Xylopia aromática (Lam.) Mart. (14), Caryocar brasiliense Cambess. (13), Copaifera langsdorffii Desf., Matayba guianensis Aubl., Qualea grandiflora Mart. (13), Casearia sylvestris Sw., Connarus suberosus Planch., Protium heptaphyllum (Aubl.) Marchand (12) e Annona coriácea Mart. (11). Contudo, 126 espécies ocorreram em apenas um dos hortos estudados (Moeda: 59 espécies; Rio Verde: 30; e Matão: 36). Exemplos de espécies exclusivas, mas com frequência elevada, são: Mabea fistulifera Mart., Jacaranda caroba (Vell.) A. DC., Maprounea guianensis Aubl. no Horto Moeda; Diospyros hispida DC., Mimosa caesalpiniifolia Benth., Vatairea macrocarpa (Benth.) Duckeno Horto Rio Verde; e Styrax camporum Pohl, Chomelia pohliana Müll. Arg., Attalea 
Tabela 1 - Espécies encontradas e sua ocorrência (número de registros) nos fragmentos do Cerrado no Leste de Mato Grosso do Sul, Brasil. Hábito: Arv: árvore; Arvt: arvoreta; Arb: arbusto; Sarb: subarbusto; Herb: herbáceo; Lian: lianescente (inclui arbustos escandentes); e Par: parasita. Fitofisionomia: 1 = Buritizal; 2 = Campo sujo; 3 = Campo úmido; 4 = Cerradão; 5 = Cerrado sensu stricto; e $6=$ Cerrado sensu stricto transição para Cerradão. Hortos: I = Moeda; II = Rio Verde; e III = Matão. Valores entre parênteses referentes ao número do coletor da série de J.G. Rando \& R.A.F. Lima. Legenda: * = espécies encontradas durante o levantamento sociológico; $\dagger$ e $\S=$ espécies muito comuns (frequência $>50 \%$ ) e espécies indicadoras de solos mesotróficos, respectivamente, segundo Ratter et a1. (2003)

Table 1 - Species list and its frequencies (number of records) in the Cerrado fragments in Eastern Mato Grosso do Sul, Brazil. Life form: Arv: tree; Arvt: treelet; Arb: shrub; Sarb: subshrub; Herb: herb; Lian: liana (scandentshrubs included); Par: parasites. Cerrado physiognomy: 1 = 'Buritizal'; 2 = 'Campo sujo'; 3 = 'Campo úmido'; 4 = 'Cerradão'; 5 = 'Cerrado sensu stricto'; 6 = 'Cerrado sensu stricto' transition to 'Cerradão'. Sites: I = Moeda; $I I=$ Rio Verde ; e III = Matão. In parentheses, the collector's numbers of J.G. Rando \& R.A.F. Lima. Legends: $*$ = species sampled during the phytosociological survey; $\dagger$ and $\S=$ very common (frequency $>50 \%$ ) and mesotrophicsoil indicator species, respectively, according to Ratter et al. (2003)

\begin{tabular}{|c|c|c|c|c|c|c|c|c|c|c|}
\hline \multirow{2}{*}{ Família, espécie e autor $\left(\mathrm{n}^{0}\right.$ do coletor $)$} & \multirow{2}{*}{ Háb. } & \multicolumn{6}{|c|}{ Fitofisionomia } & \multicolumn{3}{|c|}{ Horto } \\
\hline & & 1 & 2 & 3 & 4 & 5 & 6 & $\mathbf{I}$ & II & III \\
\hline \multicolumn{11}{|l|}{ ANACARDIACEAE } \\
\hline Astronium fraxinifolium Schott. ex Spreng $(302) * \dagger \S$ & Arv & & & & & 2 & & 1 & & 1 \\
\hline Schinus molleoides Vell. * (= Lithrea molleoides (Vell.) Engl.) & Arvt & & & & & 1 & & 1 & & \\
\hline Tapirira guianensis Aubl. * & Arv & & 1 & & & 4 & 1 & 2 & 1 & 3 \\
\hline \multicolumn{11}{|l|}{ ANNONACEAE } \\
\hline Annona coriacea Mart. $* \dagger$ & Arvt & & 2 & & & 7 & 2 & 3 & 4 & 4 \\
\hline Annona crassiflora Mart. & Arvt & & 1 & & & & & & 1 & \\
\hline Annona dioica A.St.-Hil. (304) * & Arvt & & & 1 & & 1 & & & & 2 \\
\hline Duguetia furfuracea (A. St.-Hil) Saff. * & Arvt & & 2 & & & 4 & 1 & 1 & 2 & 4 \\
\hline Xylopia aromatica (Lam.) Mart. $* \dagger$ & Arvt & 1 & & & & 10 & 3 & 5 & 5 & 4 \\
\hline Xylopia brasiliensis Spreng. & Arvt & & 1 & & & 2 & & & & 3 \\
\hline Xylopia emarginata Mart. (305) & Arvt & 1 & & 1 & & & & 1 & & 1 \\
\hline \multicolumn{11}{|l|}{ APOCYNACEAE } \\
\hline Aspidosperma cf. discolor A. DC. (480) & Arv & & & & & & 1 & & 1 & \\
\hline Aspidosperma cf. subincanum Mart. (306) § & Arv & & & & & 1 & & 1 & & \\
\hline Aspidosperma tomentosum Mart. (482) $* \dagger$ & Arvt & & & & & 1 & 1 & 1 & & 1 \\
\hline Hancornia speciosa B.A. Gomes (307) $* \dagger$ & Arv & & & & & & 1 & 1 & & \\
\hline \multicolumn{11}{|l|}{ AQUIFOLIACEAE } \\
\hline Ilex affinis Gardner (309) & Arvt & & & & & 1 & & 1 & & \\
\hline \multicolumn{11}{|l|}{ ARALIACEAE } \\
\hline Dendropanax cuneatus (DC.) Dcne. et Planch. (311) & Arv & 1 & & & & & & 1 & & \\
\hline $\begin{array}{l}\text { Schefflera vinosa (Cham. \& Schltdl.) Frodin \& Fiaschi (310) * } \\
\text { ARECACEAE }\end{array}$ & Arv & & 1 & & & & 2 & 1 & 1 & 1 \\
\hline Acrocomia aculeata (Jacq.) Lodd.ex Mart.§ & Arv & & 1 & & & 1 & 1 & & 2 & 1 \\
\hline Attalea phalerata Mart. ex Spreng. § & Arvt & & 1 & & & 2 & & & & 3 \\
\hline Butia paraguariensis (Barb. Rodr.) L.H. Bayley & Arvt & & & & & 1 & & & & 1 \\
\hline Mauritia flexuosa L. f. & Arv & 1 & 1 & & & 2 & & 1 & & 3 \\
\hline Syagrus flexuosa (Mart.) Becc. * & Arvt & & & & & 4 & 1 & 2 & 1 & 2 \\
\hline \multicolumn{11}{|l|}{ ARISTOLOCHIACEAE } \\
\hline Aristolochia esperanzae Kuntze (314) & Lian & & & & & 2 & & 1 & 1 & \\
\hline Aristolochia sp. & Lian & & & & & & 1 & 1 & & \\
\hline \multicolumn{11}{|l|}{ ASTERACEAE } \\
\hline Achyrocline satureioides (Lam.) DC. & Arvt & & & & & 1 & & & & 1 \\
\hline Baccharis dracunculifolia DC. (315) & Arb & & 1 & & & 2 & & & & 3 \\
\hline Bidens gardneri Backer & Arb & & 1 & & & & & & & 1 \\
\hline Eupatorium squalidum DC. (316) * & Arb & & & & & 1 & & & & 1 \\
\hline
\end{tabular}


Tabela 1 - Cont.

Table 1 - Cont.

\begin{tabular}{|c|c|c|c|c|c|c|c|c|c|c|}
\hline \multirow{2}{*}{ Família, espécie e autor ( $n^{\circ}$ do coletor) } & \multirow{2}{*}{ Háb. } & \multicolumn{6}{|c|}{ Fitofisionomia } & \multicolumn{3}{|c|}{ Horto } \\
\hline & & 1 & 2 & 3 & 4 & 5 & 6 & $\mathbf{I}$ & II & III \\
\hline Gochnatia polymorpha (Less.) Cabrera * & Arv & & & & & & 1 & 1 & & \\
\hline $\begin{array}{l}\text { Vernonia rubriramea Mart. ex DC. }(317,318) * \\
\text { BALANOPHORACEAE }\end{array}$ & Arb & & & & & 5 & 2 & 2 & 1 & 4 \\
\hline $\begin{array}{l}\text { Langsdorffia hypogaea Mart. (321) } \\
\text { BIGNONIACEAE }\end{array}$ & Par & & & & & 1 & & & 1 & \\
\hline Anemopaegma arvense (Vell.) Stellfeld ex de Souza (324) & Lian & & 1 & & & & & 1 & & \\
\hline Anemopaegma glaucum Mart. ex DC. (325) & Lian & & 1 & & & & & 1 & & \\
\hline Arrabidaea brachypoda (DC.) Bureau (322) & Lian & & & & 1 & & & 1 & & \\
\hline Arrabidaea sp. (323) & Lian & & & & & & 1 & & 1 & \\
\hline Jacaranda caroba (Vell.) A. DC. $(328,330) *$ & Arb & 1 & & & & 1 & 2 & 4 & & \\
\hline Pithecoctenium crucigerum (L.) A.H. Gentry & Lian & & 1 & & & & & 1 & & \\
\hline Tabebuia caraiba (Mart.) Bureau (326) * & Arv & & 1 & & & 5 & & 4 & 2 & \\
\hline Tabebuia ochracea (Cham.) Standl. *† & Arv & & 1 & & & 7 & & 1 & 2 & 5 \\
\hline Tabebuia roseoalba (Rid.) Sandw. $(119,329) *$ & Arv & & & & & 1 & 1 & & 1 & 1 \\
\hline Tabebuia sp.1 (75) & Arv & & & & 2 & & & 2 & & \\
\hline Tabebuia sp.2 & Arv & & & & 1 & & & 1 & & \\
\hline $\begin{array}{l}\text { Tabebuia vellosoii Toledo (327) } \\
\text { BIXACEAE }\end{array}$ & Arv & & & & & & 1 & 1 & & \\
\hline $\begin{array}{l}\text { Cochlospermum regium (Schrank) Pilger (335) } \\
\text { BROMELIACEAE }\end{array}$ & Sarb & & 1 & & & 4 & & 1 & 1 & 3 \\
\hline $\begin{array}{l}\text { Bromelia balansae Mez } \\
\text { BURSERACEAE }\end{array}$ & Herb & & & & & 1 & & 1 & & \\
\hline $\begin{array}{l}\text { Protium heptaphyllum (Aubl.) Marchand }(125,331,332) * \\
\text { CACTACEAE }\end{array}$ & Arvt & 1 & 1 & & 1 & 7 & 2 & 4 & 2 & 6 \\
\hline $\begin{array}{l}\text { Cereus peruvianus Mart. * } \\
\text { CANNABACEAE }\end{array}$ & Arb & & & & & 1 & & 1 & & \\
\hline Celtis cf. iguanae (Jacq.) Sarg. & Arvt & & & & & & 1 & & 1 & \\
\hline $\begin{array}{l}\text { Trema micrantha }(\mathrm{L} .) \text { Blume } \S \\
\text { CARYOCARACEAE }\end{array}$ & Arvt & & 1 & & & & & & & 1 \\
\hline $\begin{array}{l}\text { Caryocar brasiliense Cambess. (20) } * \dagger \\
\text { CELASTRACEAE }\end{array}$ & Arv & & 2 & & & 9 & 2 & 4 & 3 & 6 \\
\hline Hippocratea volubilis L. (333) & Lian & & & & 1 & & & 1 & & \\
\hline $\begin{array}{l}\text { Plenckia populnea Reissek (334) } \\
\text { CHRYSOBALANACEAE }\end{array}$ & Arv & & 1 & & & 3 & & 1 & & 3 \\
\hline Hirtella gracilipes (Hook.) Prance (342) * & Sarb & & & 1 & & 1 & & & & 2 \\
\hline $\begin{array}{l}\text { Licania humilis Cham. \& Schltdl. } \\
\text { CLUSIACEAE }\end{array}$ & Arv & & & & & 1 & & 1 & & \\
\hline Calophyllum brasiliense Cambess. & Arv & 1 & 1 & & & & & 1 & & 1 \\
\hline $\begin{array}{l}\text { Kielmeyera variabilis Mart. } \\
\text { COMBRETACEAE }\end{array}$ & Arvt & & & & & 1 & 1 & 1 & 1 & \\
\hline Buchenavia tomentosa Eichler $(159,338) *$ & Arv & 1 & & & & 2 & & 1 & 2 & \\
\hline $\begin{array}{l}\text { Terminalia argentea Mart. (337) *§ } \\
\text { CONNARACEAE }\end{array}$ & Arv & & & & 1 & 2 & 1 & 3 & 1 & \\
\hline Connarus suberosus Planch. (430) $* \dagger$ & Arv & & & & & 10 & 2 & 2 & 5 & 5 \\
\hline $\begin{array}{l}\text { Rourea induta Planch. (482) } \\
\text { CONVOLVULACEAE }\end{array}$ & Arv & & & & & 1 & & & & 1 \\
\hline $\begin{array}{l}\text { Cuscuta racemosa Mart.(538) } \\
\text { COSTACEAE }\end{array}$ & Lian & & 1 & & & & & & 1 & \\
\hline Costus spiralis (Jacq.) Roscoe & Herb & & 1 & & & & & & & 1 \\
\hline
\end{tabular}

Revista Árvore, Viçosa-MG, v.39, n.1, p.9-24, 2015 
Tabela 1 - Cont.

Table 1 - Cont.

\begin{tabular}{|c|c|c|c|c|c|c|c|c|c|c|}
\hline \multirow{2}{*}{ Família, espécie e autor ( $n^{\circ}$ do coletor) } & \multirow{2}{*}{ Háb. } & \multicolumn{6}{|c|}{ Fitofisionomia } & \multicolumn{3}{|c|}{ Horto } \\
\hline & & 1 & 2 & 3 & 4 & 5 & 6 & $\mathbf{I}$ & II & III \\
\hline \multicolumn{11}{|l|}{ DILLENIACEAE } \\
\hline Curatella americana L. $(341) \dagger$ & Arv & & 1 & & & 1 & & & 1 & 1 \\
\hline Davilla elliptica A.St.-Hil. (340) $* \dagger$ & Arb & & 1 & & & 3 & 1 & 1 & 1 & 3 \\
\hline Doliocarpus dentatus (Aubl.) Standl. & Lian & & & & 1 & & & 1 & & \\
\hline \multicolumn{11}{|l|}{ EBENACEAE } \\
\hline Diospyros brasiliensis Mart. (344)* & Arvt & & & & & 1 & & & 1 & \\
\hline Diospyros hispida DC. (343) $* \dagger$ & Arvt & & & & & 3 & 1 & & 4 & \\
\hline \multicolumn{11}{|l|}{ ERIOCAULACEAE } \\
\hline Paepalanthus cf. lamarckii Kunth (361) & Herb & & & 1 & & & & & & 1 \\
\hline Paepalanthus sp. (359) & Herb & & & 1 & & & & & & 1 \\
\hline Syngonanthus gracilis (Bong.) Ruhland (362) & Herb & & & 1 & & & & & & 1 \\
\hline Syngonanthus helminthorrhizus (Mart.) Ruhland (360) & Herb & & & 1 & & & & & & 1 \\
\hline \multicolumn{11}{|l|}{ ERYTHROXYLACEAE } \\
\hline Erythroxylum cf. campestre A. St.-Hil. (356) * & Arb & & & & & 1 & & & & 1 \\
\hline Erythroxylum cf. daphnites Mart. (355)* & Arb & & & & 1 & 6 & & 2 & 1 & 4 \\
\hline Erythroxylum cuneifolium (Mart.) O. E. Schulz (354) & Arb & & & & 1 & 1 & & 1 & 1 & \\
\hline Erythroxylum suberosum A. St.-Hil. $(353,357,358) * \dagger$ & Arb & & & & 1 & 2 & 3 & 5 & 1 & \\
\hline Erythroxylum tortuosum Mart. * & Arb & & 1 & & & 6 & 1 & & 3 & 5 \\
\hline \multicolumn{11}{|l|}{ EUPHORBIACEAE } \\
\hline Actinostemon communis (Müll. Arg.) Pax $(345,346)$ & Arb & & & & 1 & & & 1 & & \\
\hline Alchornea glandulosa Poepp. & Arv & & & & 1 & & & 1 & & \\
\hline Croton cf. floribundus Spreng. (349) & Arv & 1 & & & & & & 1 & & \\
\hline Mabea fistulifera Mart. $(351,352)^{*}$ & Arvt & & & & 1 & & 2 & 3 & & \\
\hline Maprounea guianensis Aubl. (350) * & Arv & 1 & & & 1 & 1 & 1 & 4 & & \\
\hline Sebastiania sp. (348) & Herb & 1 & & & & & & 1 & & \\
\hline \multicolumn{11}{|l|}{ FABACEAE/CAESALPINIOIDEAE } \\
\hline Bauhinia cf. bauhinioides (Mart.) J.F. Macbr. (169) & Arb & & & & & 1 & & & 1 & \\
\hline Bauhinia holophylla (Bong.) Steud. (432) * & Arb & & & & & 2 & 3 & 1 & 4 & \\
\hline Bauhinia longifolia D. Dietr. (431)* & Arvt & & & & 2 & 1 & 1 & 3 & 1 & \\
\hline Bauhinia rufa (Bong.) Steud. (81)* & Arvt & & 1 & & 1 & 7 & 1 & 1 & 3 & 6 \\
\hline Bauhinia sp. * & Arvt & & & & & & 1 & & 1 & \\
\hline Chamaecrista desvauxii (Collad.) Killip (427) & Herb & & & & & & 1 & 1 & & \\
\hline Chamaecrista flexuosa (L.) Greene (426) & Herb & 1 & & & & & & 1 & & \\
\hline Chamaecrista ramosa (Vogel) H.S. Irwin \& Barneby & Herb & & & & & & 1 & 1 & & \\
\hline Copaifera langsdorffii Desf. $(416,417) *$ & Arv & & 1 & & 1 & 9 & 2 & 3 & 5 & 5 \\
\hline Dimorphandra mollis Benth. $* \dagger$ & Arv & & 1 & & & 2 & 2 & 3 & 2 & \\
\hline Diptychandra aurantiaca Tul. (408) & Arv & & & & & 5 & 1 & 1 & 2 & 3 \\
\hline Hymenaea courbaril L. & Arv & & & & 1 & 2 & & 2 & 1 & \\
\hline Hymenaea stigonocarpa Mart. ex Hayne (15) $* \dagger$ & Arv & & 1 & & & 6 & 2 & 2 & 4 & 3 \\
\hline Peltophorum dubium (Spreng.) Taub. (421) & Arv & & & & & & 1 & & & 1 \\
\hline Senna rugosa (G. Don) H.S. Irwin \& Barneby (413) & Arb & & 1 & & & 4 & 2 & 1 & 3 & 3 \\
\hline Senna velutina (Vogel) H.S. Irwin \& Barneby (429) & Arb & & 1 & & 1 & 1 & 1 & 2 & 2 & \\
\hline \multicolumn{11}{|l|}{ FABACEAE/FABOIDEAE } \\
\hline Acosmium subelegans (Mohlenbr.) Yakovlev (411) * & Arv & & & & & 2 & 2 & 1 & 2 & 1 \\
\hline Andira cujabensis Benth. (540)* & Arv & & & & & 4 & 1 & 1 & 4 & \\
\hline Bowdichia virgilioides Kunth (415) $\dagger$ & Arv & & & & & 2 & 2 & 1 & 3 & \\
\hline Camptosema ellipticum (Desv.) Burkart (428) & Lian & & & & & 2 & & & 1 & 1 \\
\hline Dioclea glabra Mart. & Lian & & & & & 1 & & & 1 & \\
\hline Dipteryx alata Vogel. $\S$ & Arv & & & & & 1 & 2 & 1 & 2 & \\
\hline
\end{tabular}


Tabela 1 - Cont.

Table 1 - Cont.

\begin{tabular}{|c|c|c|c|c|c|c|c|c|c|c|}
\hline \multirow{2}{*}{ Família, espécie e autor ( $n^{\circ}$ do coletor $)$} & \multirow{2}{*}{ Háb. } & \multicolumn{6}{|c|}{ Fitofisionomia } & \multicolumn{3}{|c|}{ Horto } \\
\hline & & $\mathbf{1}$ & 2 & 3 & 4 & 5 & 6 & $\mathbf{I}$ & II & III \\
\hline Machaerium aculeatum Raddi & Arv & & & & & 1 & & 1 & & \\
\hline Machaerium acutifolium Vogel $* \dagger$ & Arv & & & & 1 & 3 & 2 & 3 & 3 & \\
\hline Machaerium opacum Vogel (423)* & Arv & & & & & 3 & & & & 3 \\
\hline Ormosia arborea (Vell.) Harms & Arv & & & & & 1 & & 1 & & \\
\hline Platypodium elegans Vogel (418) § & Arv & 1 & & & 1 & 1 & 2 & 3 & 2 & \\
\hline Pterodon pubescens (Benth.) Benth. (422)* & Arv & & & & & 2 & 3 & 1 & 2 & 2 \\
\hline Vatairea macrocarpa (Benth.) Ducke (407) $* \dagger$ & Arv & & & & & 2 & & & 2 & \\
\hline FABACEAE/MIMOSOIDEAE & & & & & & & & & & \\
\hline Acacia polyphylla DC. & Arv & & & & 1 & & & 1 & & \\
\hline Albizia hasslerii (Chodat) Burkart $\S$ & Arv & & & & 1 & & & 1 & & \\
\hline Anadenanthera falcata (Benth.) Spreng. (414)* & Arv & & & & 1 & 1 & 3 & 3 & 2 & \\
\hline Enterolobium gummiferum (Mart.) J.F. Macbr. (409) & Arv & & & & & 2 & & & & 2 \\
\hline Mimosa caesalpiniifolia Benth. * & Arvt & & & & & 3 & & & 3 & \\
\hline Mimosa hebecarpa Benth. (425) * & Arvt & & & & & 1 & 1 & 1 & & 1 \\
\hline Mimosa sp. (424) & $\mathrm{Nc}$ & & & & & 1 & & & & 1 \\
\hline Plathymenia reticulata Benth. $(24,410) * \dagger$ & Arv & & & & & 3 & 1 & 1 & 1 & 2 \\
\hline $\begin{array}{l}\text { Stryphnodendron polyphyllum Mart. (412) * } \\
\text { GENTIANACEAE }\end{array}$ & Arv & & 2 & & & 4 & 1 & 2 & 1 & 4 \\
\hline $\begin{array}{l}\text { Schultesia guianensis (Aubl.) Malme } \\
\text { LAMIACEAE }\end{array}$ & Herb & & & 2 & & & & & & 2 \\
\hline $\begin{array}{l}\text { Aegiphila lhotzkiana Cham. * } \\
\text { LAURACEAE }\end{array}$ & Arvt & & & & & & 1 & 1 & & \\
\hline Aiouea trinervis Meisn. (405)* & Arb & & 1 & & & 3 & 1 & & 2 & 3 \\
\hline Nectandra cuspidata Nees \& Mart. $(366,402)$ & Arv & 2 & & & & & & 2 & & \\
\hline Ocotea corymbosa (Meisn.) Mez (367)* & Arv & & & & & & 1 & 1 & & \\
\hline Ocotea minarum (Nees \& Mart.) Mez $(162,403,404) *$ & Arv & & & & & 4 & 1 & 3 & 1 & 1 \\
\hline $\begin{array}{l}\text { Ocotea velloziana (Meisn.) Mez }(141,160,365) \\
\text { LECYTHIDACEAE }\end{array}$ & Arv & & 1 & & & & & & 1 & \\
\hline $\begin{array}{l}\text { Eschweilera nana (O. Berg) Miers (433) } \\
\text { LOGANIACEAE }\end{array}$ & Arv & & & & & 1 & & & 1 & \\
\hline $\begin{array}{l}\text { Strychnos brasiliensis (Spreng.) Mart. (406) } \\
\text { LYTHRACEAE }\end{array}$ & Arb & & & & & 1 & & & 1 & \\
\hline $\begin{array}{l}\text { Lafoensia pacari A. St.-Hil. } \dagger \\
\text { MAGNOLIACEAE }\end{array}$ & Arv & & & & & 1 & & & 1 & \\
\hline $\begin{array}{l}\text { Magnolia ovata (A. St.-Hil) Spreng. } \\
\text { MALPIGHIACEAE }\end{array}$ & Arv & & & 1 & & & & & & 1 \\
\hline Banisteriopsis pubipetala (A. Juss.) Cuatr. (535) & Lian & & & & & & 2 & 2 & & \\
\hline Byrsonima basiloba A. Juss. (437) * & Arvt & & & & & 4 & & & 2 & 2 \\
\hline Byrsonima cf. crassifolia (L.) Kunth (443) & Arvt & & & & & & 1 & & 1 & \\
\hline Byrsonima cf. verbascifolia (L.) DC. (442) $\dagger$ & Arvt & & & & & 1 & & & & 1 \\
\hline Byrsonima coccolobifolia (L.) Kunth $(434,436) * \dagger$ & Arvt & 1 & 1 & & & 3 & 1 & 2 & & 4 \\
\hline Byrsonima intermedia A. Juss. (444) * & Arvt & 1 & 1 & & & 5 & 1 & 2 & 2 & 4 \\
\hline Heteropterys byrsonimifolia A. Juss. (440) & Arb & & 2 & & & 4 & & 2 & 1 & 3 \\
\hline Mascagania cordifolia (A. Juss.) Griseb. (439) & Arb & & & & 1 & & & 1 & & \\
\hline $\begin{array}{l}\text { Peixotoa reticulata Griseb. }(438,439) \\
\text { MALVACEAE }\end{array}$ & Lian & & 1 & & & 3 & 2 & 2 & 3 & 1 \\
\hline Eriotheca gracilipes (K. Schum.) A. Robyns (29) $* \dagger$ & Arv & & 2 & & & 6 & 2 & 3 & 3 & 4 \\
\hline Guazuma ulmifolia Lam.(446) § & Arvt & & & & & 1 & & & 1 & \\
\hline Luehea divaricata Mart. \& Zucc. (447)* & Arv & & & & & 1 & 1 & 1 & 1 & \\
\hline
\end{tabular}

Revista Árvore, Viçosa-MG, v.39, n.1, p.9-24, 2015 
Tabela 1 - Cont.

Table 1 - Cont

\begin{tabular}{|c|c|c|c|c|c|c|c|c|c|c|}
\hline \multirow{2}{*}{ Família, espécie e autor ( $n^{\circ}$ do coletor $)$} & \multirow{2}{*}{ Háb. } & \multicolumn{6}{|c|}{ Fitofisionomia } & \multicolumn{3}{|c|}{ Horto } \\
\hline & & 1 & 2 & 3 & 4 & 5 & 6 & $\mathbf{I}$ & II & III \\
\hline Luehea grandiflora Mart. (448) $\S$ & Arv & & & & 1 & 2 & 1 & 1 & 3 & \\
\hline Lueheopsis hoehnei Burret (445) & Arv & & & 1 & & & & & & 1 \\
\hline $\begin{array}{l}\text { Pseudobombax longiflorum (Mart. \& Zucc.) A. Robyns } \\
\text { MELASTOMATACEAE }\end{array}$ & Arv & & & & & 2 & & & & 2 \\
\hline Macairea radula (Bonpl.) DC. (453) & Arb & 1 & & & & & 1 & 2 & & \\
\hline Miconia albicans (Sw.) Triana (451)* & Arb & 1 & 1 & & & 5 & 2 & 2 & 3 & 4 \\
\hline Miconia chamissois Naudin (454) & Arvt & 1 & & & & & & 1 & & \\
\hline Miconia stenostachya DC. (452) & Arb & & & & & 1 & 1 & 1 & 1 & \\
\hline $\begin{array}{l}\text { Microlicia isophylla DC. } \\
\text { MELIACEAE }\end{array}$ & Sarb & & & & & & 1 & 1 & & \\
\hline Guarea guidonia (L.) Sleumer (449) & Arv & 1 & & & & 1 & & 2 & & \\
\hline $\begin{array}{l}\text { Trichilia pallida } \mathrm{Sw} .(450) * \\
\text { MORACEAE }\end{array}$ & Arv & & & & & 1 & 2 & 2 & 1 & \\
\hline Brosimum gaudichaudii Trécul (456) $* \dagger$ & Arb & 1 & 1 & & 1 & 4 & 1 & 4 & 1 & 3 \\
\hline Brosimum sp. & $\mathrm{Nc}$ & & & & & 1 & & & 1 & \\
\hline Ficus guaranitica Chodat (455) & Arv & & & & & 1 & & & 1 & \\
\hline MYRISTICACEAE & & & & & & & & & & \\
\hline $\begin{array}{l}\text { Virola sebifera Aubl. (489) * } \\
\text { MYRSINACEAE }\end{array}$ & Arv & & 1 & 1 & & & 1 & 1 & & 2 \\
\hline Rapanea ferruginea (Ruiz \& Pav.) Mez & Arvt & & & & & 1 & & & 1 & \\
\hline $\begin{array}{l}\text { Rapanea guianensis Aubl. (544)* } \\
\text { MYRTACEAE }\end{array}$ & Arv & 1 & & & 1 & 3 & 1 & 4 & 2 & \\
\hline Eugenia aurata O. Berg (462)* & Arv & & & & & 1 & & & 1 & \\
\hline Eugenia bimarginata DC. (458) & Arv & & 1 & & & & & 1 & & \\
\hline Eugenia florida DC. (459) * & Arb & & & & & 2 & & 1 & 1 & \\
\hline Eugenia sp.1 (463) & Arb & & & & & 1 & & 1 & & \\
\hline Eugenia sp.3 (472)* & Arb & & & & & 1 & & & 1 & \\
\hline Eugenia sp.4 (473)* & Arb & & & & & 3 & & & 2 & 1 \\
\hline Eugenia uniflora L. (467) & Arv & & & & & 2 & & & & 2 \\
\hline Myrcia albotomentosa DC. (461) & Arv & & & & & 1 & & 1 & & \\
\hline Myrciamultiflora (Lam.) DC. (468)* & Arv & & & & & & 1 & 1 & & \\
\hline Myrcia sp.1 (457) * & Arb & & & & & 1 & & & 1 & \\
\hline Myrcia sp.2 (470)* & Arb & & & & & 4 & 1 & 2 & 3 & \\
\hline Myrciasubcordata DC. (471)* & Arv & & & & & 3 & & 1 & 1 & 1 \\
\hline Myrtaceae sp. $1 *$ & Arv & & & & & 2 & & & 1 & 1 \\
\hline Myrtaceae sp. $2 *$ & Arb & & & & & 4 & & & 1 & 3 \\
\hline Myrtaceae sp. $3 *$ & Arb & & & & & 2 & & 1 & 1 & \\
\hline Myrtaceae sp. $4 *$ & Arb & & & & & 5 & & & 2 & 3 \\
\hline Psidium guineense Pers. (464) & Arvt & & & & & 1 & & 1 & & \\
\hline Psidium sp. (466) & Arb & & & & & 1 & & 1 & & \\
\hline NYCTAGINACEAE & & & & & & & & & & \\
\hline Guapira noxia (Netto) Lundell (490) & Arv & & & & & & 1 & 1 & & \\
\hline $\begin{array}{l}\text { Guapira opposita (Vell.) Reitz * } \\
\text { OCHNACEAE }\end{array}$ & Arv & & & & & 1 & 1 & 2 & & \\
\hline Ouratea castaneifolia (DC.) Engl. (492) & Arv & & & & & & 1 & 1 & & \\
\hline Ouratea hexasperma (A. St.-Hil.) Benth. (507)† & Sarb & & & & & 2 & & 1 & 1 & \\
\hline $\begin{array}{l}\text { Ouratea spectabilis (Mart. ex. Eng1.) Engl. (491)* } \\
\text { OLEACEAE }\end{array}$ & Arvt & & 2 & & & 7 & 1 & & 3 & 7 \\
\hline Chionanthus filiformis (Vell.) P.S. Green (543) & Arv & & & 1 & & & & & & 1 \\
\hline PHYLLANTHACEAE & & & & & & & & & & \\
\hline Hyeronima alchorneoides Allemão & Arv & 1 & & & & & & 1 & & \\
\hline
\end{tabular}


Tabela 1 - Cont.

Table 1 - Cont.

\begin{tabular}{|c|c|c|c|c|c|c|c|c|c|c|}
\hline \multirow{2}{*}{ Família, espécie e autor ( $\mathrm{n}^{0}$ do coletor $)$} & \multirow{2}{*}{ Háb. } & \multicolumn{6}{|c|}{ Fitofisionomia } & \multicolumn{3}{|c|}{ Horto } \\
\hline & & 1 & 2 & 3 & 4 & 5 & 6 & $\mathbf{I}$ & II & III \\
\hline \multicolumn{11}{|l|}{ PIPERACEAE } \\
\hline \multirow{2}{*}{\multicolumn{11}{|c|}{ POLYGONACEAE }} \\
\hline & & & & & & & & & & \\
\hline $\begin{array}{l}\text { Coccoloba mollis Casar. }(336,493) * \\
\text { PROTEACEAE }\end{array}$ & \multicolumn{9}{|c|}{ PROTEACEAE } & 7 \\
\hline Roupala montana Aubl. $* \dagger$ & Arv & & 1 & & & 6 & 2 & 2 & 2 & 5 \\
\hline \multicolumn{11}{|l|}{ RHAMNACEAE } \\
\hline Rhamnus sp. * & Arvt & & & & & 1 & & & & 1 \\
\hline \multicolumn{11}{|l|}{ RUBIACEAE } \\
\hline Alibertia edulis (Rich.) A. Rich ex DC. (469)* & Arvt & & 1 & & & 9 & 5 & 4 & 5 & 6 \\
\hline Alibertia macrophylla K. Schum. (475)* & Arvt & & & & & 1 & 1 & & 1 & 1 \\
\hline Alibertia sessilis (Vell.) K. Schum. (477) * & Arvt & & & & & 2 & & 1 & 1 & \\
\hline Borreria quadriculata Cabral (472) & Sarb & 1 & & & & 2 & & 1 & & 2 \\
\hline Chomelia pohliana Müll. Arg. (474)* & Arb & & & & & 4 & & & & 4 \\
\hline Guettarda viburnoides Cham. \& Schltdl. (541)*§ & Arv & & & & & 1 & & 1 & & \\
\hline Randia armata (Sw.) DC. & Arvt & & & & 1 & & & 1 & & \\
\hline $\begin{array}{l}\text { Tocoyena formosa (Cham. \& Schltdl.) K. Schum (542) *† } \\
\text { RUTACEAE }\end{array}$ & Arb & & & & & 4 & 2 & 2 & 2 & 2 \\
\hline $\begin{array}{l}\text { Zanthoxyllum riedelianum Eng1. (471) } \S \\
\text { SALICACEAE }\end{array}$ & Arv & & & & 1 & & & 1 & & \\
\hline $\begin{array}{l}\text { Casearia sylvestris Sw. }(503,504) * \dagger \\
\text { SAPINDACEAE }\end{array}$ & Arvt & & 2 & & & 8 & 2 & 3 & 6 & 3 \\
\hline Magonia pubescensA. St.-Hil. $(499,500) * \S$ & Arv & & & & & 4 & & & 1 & 3 \\
\hline Matayba guianensis Aubl. $(497,498) *$ & Arv & 2 & 1 & & & 8 & 2 & 4 & 4 & 5 \\
\hline Serjanialethalis A. St.-Hil.(496) & Lian & & 1 & & 1 & 4 & 2 & 2 & 3 & 3 \\
\hline Toulicia tomentosa Radlk. (479) & Arb & & & & 1 & & & 1 & & \\
\hline \multicolumn{11}{|l|}{ SAPOTACEAE } \\
\hline Chrysophyllum marginatum (Hook. \& Arn.) Radlk. * & Arv & & & & & 1 & & 1 & & \\
\hline Pouteria cf. gardneri (Mart. \& Miq.) Baehni (501)* & Arv & & & & & 2 & & & & 2 \\
\hline Pouteria ramiflora (Mart.) Radlk. (502) $* \dagger$ & Arv & & & & & 1 & & & & 1 \\
\hline $\begin{array}{l}\text { Pouteria torta (Mart.) Radlk. } * \\
\text { SIMAROUBACEAE }\end{array}$ & \multicolumn{9}{|c|}{ SIMAROUBACEAE } & \\
\hline Simarouba versicolor A. St.-Hil (483) & Arv & & & & & 1 & & & 1 & \\
\hline \multicolumn{11}{|l|}{ SIPARUNACEAE } \\
\hline $\begin{array}{l}\text { Siparuna guianensis Aubl. } \\
\text { SMILACACEAE }\end{array}$ & Arvt & & 1 & & & & & & & 1 \\
\hline Smilax sp. (505) & Lian & & 1 & & & 2 & 1 & & 1 & 3 \\
\hline \multicolumn{11}{|l|}{ SOLANACEAE } \\
\hline Cestrum intermedium Sendtn. & Arvt & & 1 & & & & & & 1 & \\
\hline & Arvt & & 1 & & & & & 1 & & \\
\hline $\begin{array}{l}\text { STYRACACEAE } \\
\text { Styrax camporum Pohl (485)* } \\
\text { URTICACEAE }\end{array}$ & Arvt & & 1 & & & 4 & & & & 5 \\
\hline Cecropia pachystachya Trécul & Arv & & 1 & & & & & & & 1 \\
\hline $\begin{array}{l}\text { VERBENACEAE } \\
\text { Lippia lasiocalycina Cham. (487) }\end{array}$ & Sarb & & & & & 1 & & & 1 & \\
\hline $\begin{array}{l}\text { Lippia lupulina Cham. } \\
\text { VOCHYSIACEAE }\end{array}$ & Sarb & & & & & 2 & & & & 2 \\
\hline Qualea cordata (Mart.) Spreng. (539) * & Arv & & & & & 2 & & & 2 & \\
\hline Qualea grandiflora Mart. (488) $*_{\dagger}$ & Arv & & 1 & & 1 & 9 & 2 & 2 & 6 & 5 \\
\hline Qualea multiflora Mart. $* \dagger$ & Arv & & & & & 1 & 1 & 2 & & \\
\hline Qualea parviflora Mart. $* \dagger$ & Arv & & & & & 1 & & 1 & & \\
\hline Vochysia tucanorum Mart. * & Arv & & & & & 1 & 1 & 1 & 1 & \\
\hline
\end{tabular}

Revista Árvore, Viçosa-MG, v.39, n.1, p.9-24, 2015 
phalerata Mart. ex Spreng., Machaerium opacum Vogel e Xylopia brasiliensis Spreng. no Horto Matão. Foram encontradas 14 espécies indicadoras de solos mesotróficos (sensu RATTER et al., 1997; Tabela 1), cujas proporções nos hortos estudados foram: Moeda: 0,07; Rio Verde: 0,07; e Matão: 0,06.

\subsection{Diversidade de espécies arbustivas e arbóreas}

O levantamento por parcelas nas áreas de Cerrados sensu stricto resultou num total de 651 indivíduos, pertencentes a 40 famílias, 72 gêneros e 105 espécies. Através dos estimadores Jackknife de primeira e segunda ordens, estimou-se um número total máximo de 149 e 165 espécies arbustivas e arbóreas para a região, respectivamente. Esses valores são condizentes com a riqueza de arbustos e árvores observada nos três hortos juntos, que foi de 158 espécies. Curiosamente, os três hortos apresentaram praticamente o mesmo número de espécies observadas (Tabela 2). Contudo, quando se compara o número de espécies com um mesmo número de indivíduos (rarefação), percebe-se que o Horto Matão foi aquele com maior riqueza de espécies (os demais hortos não diferiram entre si). Quanto ao índice de Shannon $\left(H^{\prime}\right)$, o horto Matão também obteve os maiores valores, seguido dos hortos Rio Verde e Moeda ( $H^{\prime}$ geral $\left.=3,81\right)$. Um padrão um pouco distinto pode ser observado para a dominância de Berger-Parker (Tabela 2).

Tabela 2 - Resultados de riqueza (observada, média e máxima), diversidade de Shannon e dominância de BergerParker. Riquezas média e máxima estimadas por rarefação $(N=175$ indivíduos) e pelo método Jackknife de primeira ordem, através de 10.000 randomizações. Letras supraescritas diferentes indicam médias estatisticamente diferentes $(\alpha=5 \%)$.

Table 2 - Richness results (observed, mean, and maximum), Shannon diversity and Berger-Parker dominance. Mean and maximum richness estimated by rarefaction ( $N=175$ individuals) and by the first order Jackknife method (10,000 randomizations). Superscript different letters indicate that means are statistically different $(\alpha=5 \%)$.

\begin{tabular}{lccc}
\hline \multirow{2}{*}{ Parâmetro } & \multicolumn{3}{c}{ Horto } \\
\cline { 2 - 4 } & Moeda & Rio Verde & Matão \\
\hline $\mathrm{S}_{\text {observada }}$ & 57 & 57 & 58 \\
$\mathrm{~S}_{\text {media }}$ & $48,8 \pm 4,8^{\mathrm{a}}$ & $53,7 \pm 2,6^{\mathrm{a}}$ & $58^{\mathrm{b}}$ \\
$\mathrm{S}_{\text {máxima }}$ & $87,6 \pm 5,7^{\mathrm{a}}$ & $79,5 \pm 4,7^{\mathrm{a}}$ & $84,9 \pm 4,9^{\mathrm{a}}$ \\
Diversidade & $3,410^{\mathrm{a}}$ & $3,522^{\mathrm{b}}$ & $3,698^{\mathrm{c}}$ \\
Dominância & $0,146^{\mathrm{ab}}$ & $0,160^{\mathrm{a}}$ & $0,125^{\mathrm{b}}$ \\
\hline
\end{tabular}

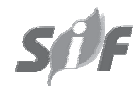

Quanto à composição, as famílias com mais de quatro espécies somaram $56 \%$ das espécies e foram: Fabaceae (20 espécies), Myrtaceae (12), Rubiaceae (seis), Vochysiaceae (cinco), Annonaceae, Bignoniaceae, Erythroxylaceae e Sapotaceae (quatro). Com alterações mínimas, essa foi a mesma ordem encontrada nos hortos individualmente. Contudo, houve considerável variação florística entre os hortos (média e desvio-padrão do índice de Chao e, entre parênteses, o índice de Sørensen): Moeda-Rio Verde: 0,53 $\pm 0,12(0,47)$; Moeda-Matão: $0,42 \pm 0,11(0,40)$; e Rio Verde-Matão: $0,51 \pm 0,11(0,49)$. Apenas o valor médio de similaridade obtido entre os hortos Moeda e Matão foi significativamente menor que entre os demais pares. Houve um número relativamente grande de espécies presentes em apenas um horto: Moeda: 20 espécies; Rio Verde: 17; e Matão: 21.

Além da composição, a análise fitossociológica evidenciou grande variação entre hortos. Essa afirmação não é verdadeira apenas entre as espécies mais abundantes (Tabela 3), de modo que os fragmentos estudados foram bastante distintos em termos sociológicos. Nos três hortos, houve tendência de poucas espécies com altos valores de importância (VI > 10), que juntas tiveram grande contribuição no VI total (Moeda: sete espécies com 41,4\% do VI total; Rio Verde: nove com 43,2\%; e Moeda: cinco com 34,5\%). Adicionalmente, a ISA revelou a presença de algumas espécies significativamente indicadoras dos hortos estudados [Moeda: Matayba guianensis, Chrysophyllum marginatum (Hook. \& Arn.) Radlk., Rapanea guianensis Aubl., Qualea multiflora Mart., Myrcia multiflora (Lam.) DC.e Maprounea guianensis; Rio Verde: Diptychandra aurantiaca Tul., Vochysia tucanorum Mart., D. hispida e Qualea cordata (Mart.) Spreng.; e Matão: Myrtaceae sp.1, Magonia pubescens A. St.-Hil., C. pohliana e Vernonia rubriramea Mart. ex DC.]. Essa diferenciação entre hortos foi confirmada pela $M R P P$, que mostrou uma dissimilaridade florística diferente do esperado pelo acaso entre os pares de hortos (Moeda-Rio Verde: $A=0,026 ; p=0,012$; Moeda-Matão: $A=0,035 ; p=$ 0,002; e Rio Verde-Matão: $A=0,020$; e $p=0,015$ ).

\section{DISCUSSÃO}

\subsection{Florística geral}

No geral, a riqueza por família encontrada nas áreas de Cerrado estudadas corroborou o padrão relatado para o Cerrado brasileiro (e.g. COSTA; ARAÚJO, 2001;

Revista Árvore, Viçosa-MG, v.39, n.1, p.9-24, 2015 
Tabela 3 - Parâmetros sociológicos das espécies mais abundantes por horto. São apresentadas, em ordem decrescente de densidade relativa total, apenas as espécies entre as 10 mais abundantes em cada horto. Legenda: $D r=$ Densidade relativa; $\mathrm{Fr}=$ Frequência relativa; $\mathrm{DoR}=$ Dominância relativa; e VI = Valor de importância (todos os valores em porcentagem). Hortos: I = Moeda; II = Rio Verde; e III = Matão.

Table 3 - Sociological parameters of the most abundant species per site. Only the 10 most abundant species in each site are shown, in decreasing order of total relative density. Subtitle: $\mathrm{Dr}=$ Relative density; Fr = Relative frequency; DoR: Relative dominance; and VI = value of importance (all values in percentage). Sites: $I=$ 'Moeda'; $I I=$ 'Rio Verde'; and III = 'Matão'.

\begin{tabular}{|c|c|c|c|c|c|c|c|c|c|c|c|c|}
\hline \multirow{2}{*}{ Espécies } & \multicolumn{3}{|c|}{ Dr } & \multicolumn{3}{|c|}{$\mathrm{Fr}$} & \multicolumn{3}{|c|}{ DoR } & \multicolumn{3}{|c|}{ VI } \\
\hline & $\mathrm{I}$ & II & II & $\mathrm{I}$ & II & II & $\mathrm{I}$ & II & II & $\mathrm{I}$ & II & II \\
\hline Matayba guianensis & 17,88 & 7,08 & 1,98 & 7,08 & 4,10 & 2,46 & 3,07 & 0,93 & 0,69 & 9,34 & 4,04 & 1,78 \\
\hline Coccoloba mollis & 5,96 & 2,06 & 9,24 & 3,54 & 3,28 & 4,92 & 12,06 & 2,81 & 11,39 & 7,19 & 2,72 & 8,88 \\
\hline Diptychandra aurantiaca & 1,55 & 14,75 & 2,64 & 0,88 & 4,10 & 2,46 & 0,09 & 20,33 & 3,14 & 0,84 & 13,06 & 2,86 \\
\hline Xylopia aromatica & 6,99 & 3,83 & 1,65 & 5,31 & 4,10 & 4,10 & 8,45 & 3,84 & 22,71 & 6,92 & 3,92 & 9,89 \\
\hline Mabea fistulifera & 10,10 & - & - & 1,77 & - & - & 5,84 & - & - & 5,90 & - & - \\
\hline Qualea grandiflora & 1,04 & 5,01 & 2,97 & 2,65 & 4,10 & 1,64 & 2,74 & 5,22 & 3,62 & 2,14 & 4,78 & 2,86 \\
\hline Alibertia edulis & 2,85 & 3,24 & 2,97 & 4,42 & 4,10 & 2,46 & 2,35 & 2,72 & 1,45 & 3,21 & 3,36 & 2,39 \\
\hline Roupala montana & 3,37 & 3,54 & 2,64 & 3,54 & 2,46 & 2,46 & 1,30 & 2,90 & 0,59 & 2,74 & 2,97 & 1,98 \\
\hline Tabebuia roseoalba & - & - & 5,28 & - & - & 0,83 & - & - & 9,52 & - & - & 5,42 \\
\hline Rapanea guianensis & 3,63 & 2,36 & - & 5,31 & 1,64 & - & 2,81 & 1,70 & - & 3,92 & 1,90 & - \\
\hline Vochysia tucanorum & - & 7,08 & - & - & 2,46 & - & - & 5,21 & - & - & 4,91 & - \\
\hline Myrtaceae sp. 1 & - & 3,54 & 3,96 & - & 3,28 & 4,10 & - & 1,58 & 0,51 & - & 2,80 & 2,98 \\
\hline Casearia sylvestris & 2,59 & 3,24 & - & 1,77 & 4,10 & - & 0,75 & 2,22 & - & 1,71 & 3,19 & - \\
\hline Trichilia pallida & 5,44 & - & - & 0,88 & - & - & 0,89 & - & - & 2,40 & - & - \\
\hline Ocotea minarum & 2,59 & 1,18 & 0,66 & 3,54 & 1,64 & 0,82 & 2,40 & 0,15 & 0,07 & 2,84 & 0,99 & 0,54 \\
\hline Erythroxylum cf. daphnites & 0,78 & - & 3,96 & 1,77 & - & 3,31 & 0,66 & - & 6,49 & 1,07 & - & 4,77 \\
\hline Bauhinia rufa & - & 1,47 & 3,96 & - & 1,65 & 2,48 & - & 0,44 & 1,44 & - & 1,19 & 2,73 \\
\hline Chrysophyllum marginatum & 3,11 & - & - & 3,54 & - & - & 6,71 & - & - & 4,45 & - & - \\
\hline Qualea cordata & - & 2,95 & - & - & 2,46 & - & - & 5,19 & - & - & 3,53 & - \\
\hline Protium heptaphyllum & 3,37 & 3,54 & 2,64 & 3,54 & 2,48 & 2,48 & 1,30 & 2,90 & 0,59 & 2,74 & 2,97 & 1,98 \\
\hline
\end{tabular}

Fabaceae, a família mais rica em espécies lenhosas no Neotrópico e no Brasil (GENTRY, 1988; GIULIETTI et al., 2005), foi predominante. Pequenos desvios se referem à maior riqueza de Bignoniaceae, principalmente devido ao elevado número de lianas, e Vochysiaceae, superada aqui por Malpighiaceae, Rubiaceae, Malvaceae e Asteraceae. Esse padrão geral é bastante consistente, apesar da grande dissimilaridade florística entre localidades (FELFILI; SILVA-JÚNIOR, 1993; CASTRO et al., 1999; RATTER et al., 2003). Na área de estudo, por exemplo, apesar do grande número de espécies exclusivas a um dos hortos (126 espécies), as famílias mais ricas mantiveram-se basicamente as mesmas, considerando todas as espécies simultaneamente ou arbustos e árvores separadamente. Devido ao foco dado às espécies arbustivas e arbóreas, famílias ricas em espécies no Cerrado (e.g. Asteraceae, Cyperaceae, Poaceae e Verbenaceae) foram claramente subamostradas neste estudo (PAGOTTO; SOUZA, 2006).

Revista Árvore, Viçosa-MG, v.39, n.1, p.9-24, 2015
Algumas das espécies encontradas são consideradas raras no Cerrado (ocorrentes em apenas uma das 376 localidades listadas por Ratter et al., 2003), entre elas: Cereus peruvianus Mart., Ficus guaranítica Chodat, Miconia chamissois Naudin, Mimosa hebecarpa Benth., Ormosia arbórea (Vell.) Harms e Ocotea velloziana (Meisn.) Mez. Vale ressaltar, contudo, que algumas dessas espécies são mais comuns no Cerradão e nas florestas estacionais, revelando o caráter ecotonal da região estudada. Vale destacar ainda a primeira ocorrência do gênero Lueheopsis (Malvaceae) no Mato Grosso do Sul, ampliando a distribuição do gênero no país (SETSER, 1977). Outras espécies não constam na extensa lista apresentada por Ratter et al. (2001) e provavelmente são novas ocorrências nos Cerrados sensu stricto de Mato Grosso do Sul: Ilex affinis Gardner, Qualea cordata, Machaerium opacum e Styrax camporum. Como encontrado por outros autores (SAPORETTI-JÚNIOR etal., 2003; BORGES; SHEPHERD, 
2005; NERI et al., 2007), a inclusão de indivíduos de menor porte foi importante na descrição mais completa da flora local (33 espécies foram exclusivas aos indivíduos de menor porte) e deve ser adotada em futuros estudos do Cerrado (e.g. ROSSATTO et al., 2008).

Das 38 espécies lenhosas citadas por Ratter et al. (2003) como as mais comuns do Cerrado brasileiro, apenas cinco não foram encontradas aqui (Acosmium dasycarpum (Vogel) Yakovlev, Himatanthus obovatus (Müll.Arg.) Woodson, Kielmeyera coriácea Mart. \& Zucc., Salvertia convallariodora A.St.-Hil. e Tachigali áurea Tul.). Entre essas espécies, Xylopia aromatica, Caryocar brasiliense, Qualea grandiflora, Casearia sylvestris, Connarus suberosus e Annonacoriacea figuraram entre as mais comuns também nos hortos estudados aqui. Apesar de a proximidade com florestas do interior do Estado de São Paulo, as proporções de espécies indicadoras de solos mesotróficos foram baixas (6-7\%). Tal resultado contraria o proposto por Ratter et al. (2003) para os Cerrados de Mato Grosso do Sul e talvez esteja relacionado à predominância de solos distróficos no Leste do Estado (MERCADANTE, 1994).

\subsection{Diversidade de espécies arbustivas e arbóreas}

Um aspecto marcante deste estudo foi a baixa similaridade florística entre os hortos estudados, com valores entre 0,42 e 0,53 (índice corrigido de Chao). A MRPP também indicou assembleias distintas entre hortos. Por vezes, espécies com alta densidade relativa em um dos hortos simplesmente não estiveram presentes em outro horto. Valores de similaridade medianos a baixos têm sido citados como característica marcante para espécies lenhosas no Cerrado (FELFILI; SILVAJÚNIOR, 1993; RATTER et al., 1997; 2003). Nesse caso, contudo, tal diferenciação foi observada entre distâncias relativamente curtas (d" $60 \mathrm{~km}$ ), o que de certo modo se opõe aos resultados obtidos por Bridgewater et al. (2004) para 13 locais no Distrito Federal. Esses autores encontram valores de similaridade acima de $60 \%$ na maioria dos casos. Como discutido pelos próprios autores, esses resultados influenciam diretamente o estabelecimento de áreas para a conservação das espécies.

Os fatores que levam a essa distinção florística em distâncias tão curtas são difíceis de equacionar (FELFILI; SILVA-JÚNIOR, 1993). Além de possíveis influências relacionadas ao solo e, ou, à topografia (RATTER et al., 2003; FONSECA; SILVA-JÚNIOR, 2004;
MARIMON-JÚNIOR; HARIDASAN, 2005), dois fatores podem ter sido determinantes. Primeiramente, pouco se sabe sobre o histórico de perturbação dos fragmentos estudados, capaz de influenciar a composição de espécies (COUTINHO, 1978; OLIVEIRA et al., 2006). Sabe-se, contudo, que vários fragmentos na região foram transformados em pasto na década de 1970, enquanto outros permaneceram conservados (MERCADANTE, 1994). Contudo, não se sabe exatamente quais fragmentos estiveram submetidos a tal distúrbio. Outro importante fator é a proximidade dos fragmentos das demais formações vegetais e corpos de água (RIZZINI, 1997). O horto Moeda, por exemplo, é influenciado pelas Florestas Estacionais do Estado de São Paulo e pelo rio Paraná, que certamente condicionaram a presença de espécies como Mabea fistulifera, Maprounea guianensis, Trichilia pallida Sw., Myrcia multiflora e Guapira opposita (Vell.) Reitz.

Não houve diferenciação entre hortos no tocante à riqueza observada. Porém, o horto Matão teve maior riqueza média e maior diversidade de espécies que os demais hortos. Como exposto, distúrbios no horto Matão podem ter sido menos intensos que nos demais hortos. A densidade relativa crescente entre hortos de espécies associadas a áreas mais abertas (e.g. Xylopia aromatica e Matayba guianensis) talvez seja indicativo nesse sentido. A diferenciação entre hortos não se expressou apenas em relação à sua composição e diversidade. Houve grande variação na densidade e frequência das espécies entre hortos. Apenas Roupala Montana Aubl. e Alibertia edulis estiveram entre as mais abundantes nos três hortos. Assim, de acordo com o que foi encontrado por vários autores no Cerrado (e.g. ANDRADE et al., 2002; FELFILI et al., 2002; MARIMON-JÚNIOR; HARIDASAN, 2005; NERI et al., 2007), a identidade das espécies mais abundantes varia de uma área para outra. Neste estudo, apenas Xylopia aromatica, Qualea grandiflora e Roupala montana estiveram entre as mais abundantes em alguns dos trabalhos anteriormente citados.

Considerando apenas árvores e arbustos em Cerrado sensu stricto, os levantamentos expeditos indicaram elevada riqueza específica no Leste de Mato Grosso do Sul. Em 31 locais do Estado, Ratter et al. (2003) encontraram um número de espécies lenhosas (28-88; média $59 \mathrm{spp}$ ) quase sempre abaixo do normalmente observado (79-101; média 93 spp). Apesar das diferenças no critério de inclusão, o levantamento por parcelas reforça esse resultado, visto que estudos com esforços

Revista Árvore, Viçosa-MG, v.39, n.1, p.9-24, 2015

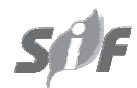


amostrais bem maiores resultaram em riquezas entre 52 e 131 espécies (média 73; ANDRADE et al., 2002; BALDUINO et al., 2005; BORGES; SHEPHERD, 2005; COSTA; ARAÚJO, 2001; FELFILI et al., 2002; FELFILI; SILVA-JÚNIOR, 1993; FONSECA; SILVA-JÚNIOR, 2004; MARIMON-JÚNIOR; HARIDASAN, 2005; NERI et al., 2007; SAPORETTI-JÚNIOR et al., 2003). A riqueza proporcional (i.e. espécies/ $N$ ) foi similar àquela encontrada por Borges e Shepherd (2005), estudo de maior riqueza entre os pesquisados. O mesmo pode ser dito sobre o índice de Shannon, que variou entre os estudos de 3,11 a 3,80 e aqui foi de 3,81. Esses resultados são válidos mesmo desconsiderando as espécies de menor porte (DAS $<3 \mathrm{~cm}$ ), o que reforça que a elevada riqueza encontrada não é apenas uma questão meramente amostral.

\section{CONCLUSÃO}

Apesar de a flora nas áreas estudadas ter seguido o padrão de riqueza por família encontrado em outras áreas do Cerrado, foi constatada elevada riqueza de espécies e heterogeneidade florística, além de novas ocorrências para o Cerrado de Mato Grosso do Sul. Esses resultados foram obtidos usando tanto o levantamento expedito quanto o levantamento por parcelas. Assim, é possível sugerir que um levantamento mais intensivo da flora arbustiva e arbórea certamente colocaria o Leste de Mato Grosso do Sul entre as áreas com maior riqueza de espécies do país, juntamente com Goiás, Tocantins e Mato Grosso. Conclui-se, portanto, que os locais estudados estão entre os mais ricos em espécies do Cerrado brasileiro, mostrando que áreas marginais de Cerrado podem ser tão ricas quanto suas áreas centrais, mesmo que através da contribuição de elementos florísticos de outras formações florestais.

\section{AGRADECIMENTOS}

À Votorantim Celulose e Papel/MS, pelo acesso aos fragmentos; e Valdeir de Souza Santos, pelo auxílio técnico em campo; aos pesquisadores Daniela Sampaio (Elaeocarpaceae), Fiorela F. Mazzine-Capelo (Myrtaceae), José R. Pirani (Rutaceae e Simaroubaceae), Lúcia G. Lohman (Bignoniaceae), Marcelo P. Ferreira (Rubiaceae), Maria S. Ferrucci (Sapindaceae e Malvaceae) e Vinicius C. Souza (diversas famílias), pelo auxílio na identificação botânica. Também, a Jim A. Ratter, pelos valiosos comentários em versões preliminares do manuscrito deste trabalho.

Revista Árvore, Viçosa-MG, v.39, n.1, p.9-24, 2015

\section{REFERÊNCIAS}

ANDRADE, L. A. Z.; FELFILI, J. M.; VIOLATTI, L. Fitossociologia de uma área de Cerrado denso na RECOR-IBGE, Brasília-DF. Acta Botanica Brasilica, v. 16, n.2, p.225-240, 2002.

APG II. An update of the Angiosperm Phylogeny Group classification for the orders and families of flowering plants: APG II. Botanical Journal of the Linnean Society, v.141, n.4, p.399-436, 2003.

BALDUINO, A.P.C.; SOUZA, A.L.; MEIRA NETO, J.A.A.; SILVA, A.F.; SILVA JÚNIOR, M.C. Fitossociologia e análise comparativa da composição florística do Cerrado da Flora de Paraopeba - MG. Revista Árvore, v.29, n.1, p.25-34, 2005.

BORGES, H. B. N.; SHEPHERD, G. J. Flora e estrutura do estrato lenhoso numa comunidade de Cerrado em Santo Antônio do Leverger, MT, Brasil. Revista Brasileira de Botânica, v.28, n.1, p.61-74, 2005.

BRIDGEWATER, S.; RATTER, J. A.; RIBEIRO, J. F. Biogeographic patterns, â-diversity and dominance in the cerrado biome of Brazil. Biodiversity and Conservation, v.13, p.2295-2318, 2004.

CASTRO, A.A.J.F.; MARTINS, F.R.; TAMASHIRO, J.Y.; SHEPHERD, G.J. How Rich is the Flora of Brazilian Cerrados? Annals of the Missouri Botanical Garden, v.86, p.192-224, 1999.

CHAO, A.; CHAZDON, R.L.; COLWELL, R.K.; SHEN, T. A new statistical approach for assessing similarity of species composition with incidence and abundance data. Ecology Letters, v.8, n.2, p.148-159, 2005.

COLWELL, R. K. EstimateS: Statistical estimation of species richness and shared species from samples. Version 7.5. http:// purl.oclc.org/estimates, 2005. Acesso em: $28 \mathrm{de}$ ago. de 2007.

COSTA, A. A.; ARAÚJO, G. M. Comparação da vegetação arbórea de Cerradão e de Cerrado na Reserva do Panga, Uberlândia, Minas Gerais. Acta Botanica Brasilica, v. 15, n.1, p.63-72, 2001. 
COUTINHO, L. M. O conceito de cerrado. Revista Brasileira de Botânica, v.1, n.1, p.17-23, 1978.

FELFILI, J. M.; SILVA JÚNIOR, M. C. A comparative study of Cerrado (Sensu stricto) vegetation in Central Brazil. Journal of Tropical Ecology, v.9, n.3, p.277-289, 1993.

FELFILI, J.M.; NOGUEIRA, P.E.; SILVA-JÚNIOR, M.C.; MARIMON, B.S.; DELITTI, W.B.C. Composição florística e fitossociologia do Cerrado sentido restrito no município de Água Boa - MT. Acta Botanica Brasilica, v.16, n.1, p.103$112,2002$.

FIASCHI, P.; PIRANI, J. R. Review of plant biogeographic studies in Brazil. Journal of Systematics and Evolution, v.47, p.1-20, 2009.

FONSECA, M. S.; SILVA-JÚNIOR, M. C. Fitossociologia e similaridade florística entre trechos de Cerrado sentido restrito em interflúvio e em vale no Jardim Botânico de Brasília, DF. Acta Botanica Brasilica, v. 18, n.1, p.19-29, 2004.

GENTRY, A. H. Changes in plant community diversity and floristic composition on environmental and geographical gradients. Annals Missouri Botanical Garden, v.75, p.1-34, 1988.

GIULIETTI, A.M.; HARLEY, R.M.; QUEIROZ, L.P.; WANDERLEY, M.G.L.; Van Den BERG, C. Biodiversidade e conservação das plantas no Brasil. Megadiversidade, v.1, n.1, p.52-61, 2005.

GOTELLI, N. J.; COLWELL, R. K. Quantifying biodiversity: procedures and pitfalls in the measurement and comparison of species richness. Ecology Letters, v.4, n.4, p.379-391, 2001.

GOTELLI, N. J.; ENTSMINGER, G. L. EcoSim: Null models software for ecology. Version 7.0. Acquired Intelligence Inc. \& Kesey-Bear, 2001. Disponível em: <http://homepages.together.net/ gentsmin/ ecosim.htm $>$ Acesso em 28 de ago. de 2007).

HARRIS, M.B.; TOMAS, W.M.; MOURÃO, G.; SILVA, C.J.; GUIMARÃES, E.; SONODA, F.; FACHIM, E. Desafios para proteger o Pantanal brasileiro: ameaças e iniciativas em conservação. Megadiversidade, v.1, n.1, p.156-164, 2005.
INSTITUTO BRASILEIRO DE GEOGRAFIA E ESTATÍSTICA - IGBE. Recursos naturais e meio ambiente: uma visão do Brasil. 2.ed. Rio de janeiro: 1997. 208p.

MARIMON-JÚNIOR, B. H.; HARIDASAN, M. Comparação da vegetação arbórea e características edáficas de um cerradão e um cerrado sensu stricto em áreas adjacentes sobre solo distrófico no leste de Mato Grosso, Brasil. Acta Botanica Brasilica, v.19, n.4, p.913-926, 2005.

McCUNE, B.; MEFFord, M. J. PcOrd: Multivariate Analysis of Ecological Data. Version 4.10. Oregon: MjM Software, 1999.

MERCADANTE, M. A. O processo de florestamento em áreas de cerrado e seus efeitos ambientais - o caso do Mato Grosso do Sul. 1994. 309f. Tese (Doutorado em Geografia Física) - Universidade de São Paulo, São Paulo, 1994.

MUELLER-DOMBOIS, D.; ELLENBERG, H. Aims and methods in plant ecology. New York: John Wiley \& Sons, 1974.

NERI, A.V.; MEIRA NETO, J.A.A.; SILVA, A.F.; MARTINS, S.V.; BATISTA, M.L. Análise da estrutura de uma comunidade lenhosa em área de cerrado sensu stricto no município de Senador Modestino Gonçalves, Norte de Minas Gerais, Brasil. Revista Árvore, v.31, n.1, p.123-134, 2007.

OLIVEIRA, M.C.; SCOLFORO, J.R.S.; MELLO, J.M.; OLIVEIRA, A.D.; ACERBI-JÚNIOR, F.W. Avaliação de diferentes níveis de intervenção na florística, diversidade e similaridade de uma área de cerrado stricto sensu. Cerne, v.12, n.4, p.342-349, 2006.

PAGOTTO, T. C. S.; SOUZA, P. R.

Biodiversidade do Complexo Aporé-

Sucuriú: subsídios à conservação e ao manejo do Cerrado (área prioritária 316 - Jauru). Campo Grande: Universidade Federal do Mato Grosso do Sul, 2006.

RATTER, J. A.; RIBEIRO, J. F.; BRIDGEWATER, S. The Brazilian Cerrado vegetation and threats to its biodiversity. Annals of Botany, v.80, p.223-230, 1997.

Revista Árvore, Viçosa-MG, v.39, n.1, p.9-24, 2015 
RATTER, J. A.; BRIDGEWATER, S.; RIBEIRO, J. F. Espécies lenhosas da fitofisionomia Cerrado sentido amplo em 170 localidades do Bioma Cerrado. Boletim do Herbário Ezechias Paulo Heringer, v.7, n.1, p.5-112, 2001.

RATTER, J. A.; BRIDGEWATER, S.; RIBEIRO, J. F. Analysis of the floristic composition of the Brazilian Cerrado vegetation III: comparison of the woody vegetation of 376 areas. Edinburgh Journal of Botany, v.60, n.1, p.57-109, 2003.

RATTER, J. A.; BRIDGEWATER, S.; RIBEIRO, J. F. Biodiversity patterns of the woody vegetation of the Brazilian Cerrado. In: PENNINGTON, R. T.;

LEWIS, G. P.; RATTER, J. A. (Ed). Neotropical savannas and seasonally dry forests: plant diversity, biogeography and conservation. Boca Raton: CRC Press, 2006. p.31-66. (The Systematics Association Special Volume, Series 69).

RIZZINI, C. T. Tratado de Fitogeografia do Brasil: aspectos ecológicos, sociológicos e florísticos. 2.ed. Rio de Janeiro: Âmbito Cultural, 1997. 747p.

ROSSATTO, D. R.; TONIATO, M. T. Z.; DURIGAN, G. Flora fanerogâmica não-arbórea do cerrado na Estação Ecológica de Assis, Estado de São Paulo. Revista Brasileira de Botânica, v. 31, n.3, p.409-424, 2008.

SAPORETTI-JÚNIOR, A. W.; MEIRA NETO, J. A. A.; ALMADO, R. P. Fitossociologia de cerrado sensu stricto no município de AbaetéMG. Revista Árvore, v.27, n.3, p.413-419, 2003.

SETSER, H. L. A Revision of Neotropical Tiliaceae: Apeiba, Luehea and Lueheopsis. 1977. 207f. Dissertação (Doutorado em Botânica) - University of Kentucky, Lexington, 1977.

VELOSO, H. P. Manual técnico da vegetação brasileira. Rio de janeiro: IBGE, 1992. 92p. (Manuais Técnicos de Geociências, 1) 